\title{
Establishment of a systemic inflammatory response syndrome model and evaluation of the efficacy of umbilical cord mesenchymal stem cell transplantation
}

\section{Guangping Ruan ( $\nabla$ ruangp@126.com )}

People's Liberation Army Joint Logistic Support Force 920th Hospital https://orcid.org/0000-0002-

3784-7040

\section{Xiang Yao}

People's Liberation Army Joint Logistic Support Force 920th Hospital

\section{Mi-yang Liu-Gao}

People's Liberation Army Joint Logistic Support Force 920th Hospital Jin-xiang Wang

People's Liberation Army Joint Logistic Support Force 920th Hospital

\section{Xue-min Cai}

People's Liberation Army Joint Logistic Support Force 920th Hospital

\section{Zi-an Li}

People's Liberation Army Joint Logistic Support Force 920th Hospital

\section{Rong-qing Pang}

People's Liberation Army Joint Logistic Support Force 920th Hospital

\section{Xing-hua Pan}

People's Liberation Army Joint Logistic Support Force 920th Hospital

\section{Research}

Keywords: systemic inflammatory response syndrome, tree shrew, model, umbilical cord mesenchymal stem cells, transplantation

Posted Date: June 4th, 2020

DOl: https://doi.org/10.21203/rs.3.rs-32086/v1

License: (c) (1) This work is licensed under a Creative Commons Attribution 4.0 International License. Read Full License 
Version of Record: A version of this preprint was published at Cells Tissues Organs on January 1st, 2021. See the published version at https://doi.org/10.1159/000514619. 


\section{Abstract}

Based on the characteristics of modern weapon injury, a repetitive model of traumatic systemic inflammatory response syndrome (SIRS) and an evaluation system were established. The models were treated with GFP-labeled tree shrew umbilical cord mesenchymal stem cells (UCMSCs). Forty out of 50 tree shrews were used to make a unilateral femoral comminuted fracture. LPS was injected intravenously to create a traumatic SIRS model. The other 10 shrews were used as normal controls. After the model was established for 10 days, 20 tree shrews were injected in the veins with GFP-labeled UCMSCs, and 18 tree shrews were not injected as the model control group. The distribution of GFP-labeled cells in vivo was measured at 2 and 10 days after injection. Twenty days after treatment, the model group, the normal control group, and the treatment group were taken to observe the pathological changes in each tissue, and blood samples were taken for the changes in liver function, renal function and heart function. Distribution of GFP-positive cells was observed in all tissues at 2 and 10 days after injection. After treatment, the HE staining results of the treatment group were close to those of the normal group, and the model group had a certain degree of lesions. The results of liver function, renal function and heart function tests in the treatment group were returned to normal, and the results in the model group were abnormally increased. UCMSCs have a certain effect on the treatment of traumatic SIRS and provide a new technical solution for modern weapon trauma treatment.

\section{Introduction:}

According to the characteristics of modern weapon injury, a repetitive systemic inflammatory response syndrome (SIRS) tree shrew model and model evaluation system were established to meet the actual needs of postwar medical protection. Blood biochemistry, histopathology and overall diagnostic indicators were screened, establishing a technical specification for the creation and evaluation of traumatic SIRS tree shrew models [1-4]. Actually, the most used animals for the development of work related to the inflammatory response are mice or rats; however, in this work, we used tree shrews. In a quick search of the current literature, it was observed that there has been an increase in the number of works using tree shrews because they have genetic similarity with primates. Tree shrews are climbing animals between insectivores and primates. Evolutionarily closer to primates than rodents, tree shrews as an alternative to primates are being considered for study [5]. Recently, the Kunming Institute of Zoology detected and analyzed the tree shrew genome [6] and proteome [7]. Tree shrews were found to have genetic characteristics close to those of primates, which laid the foundation for research into clinical disease mechanisms and the development of new drugs.

Umbilical cord mesenchymal stem cells (UCMSCs) were used to evaluate the efficacy and safety of UCMSCs in the treatment of traumatic SIRS. The treatment of trauma was established by optimizing the timing, dosage and route of treatment. A clinical treatment plan was established for traumatic SIRS [8]. The ultimate goal is to provide a new animal model for SIRS research that is reproducible and resembles the clinical features of human SIRS. Clinical transformation of UCMSC treatment technology will be 
applied. Recommendations for UCMSC war treatment were developed, and new technologies programs for modern weapon trauma treatment were provided.

Repeatable animal models for traumatic infection, systemic inflammatory response syndrome, shock, and multiple organ failure were established. New treatments based on this animal model have significant military and scientific significance. However, the use of clinical high-dose antibiotics and inflammatory factor antagonists has not effectively reduced the complications and mortality of severe trauma.

Therefore, infection is not the only cause of traumatic SIRS [9-11]. By establishing a model of traumatic systemic inflammatory response syndrome (SIRS), the efficacy and safety of umbilical cord mesenchymal stem cell therapy (UCMSC) in the treatment of traumatic SIRS could be evaluated. By optimizing the timing, dosage, and route of treatment, UCMSCs for traumatic treatment were established. The SIRS clinical treatment technology program was established. The ultimate goal is to provide a new animal model for SIRS research that is reproducible and resembles the clinical features of human SIRS. Clinical transformation of UCMSC treatment technology was applied. Recommendations for UCMSC war treatment were developed, and new technologies for modern weapon trauma treatment programs were provided.

We decided to use the impact method to make a unilateral femoral comminuted fracture and then inject LPS into the traumatic systemic inflammatory response syndrome tree shrew model to establish a model evaluation technical specification.

\section{Materials And Method:}

\section{Preparation of a tree shrew model of traumatic systemic inflammatory response syndrome:}

In total, 50 tree shrews weighing $145 \pm 11 \mathrm{~g}$ were purchased from the Kunming Institute of Zoology, Chinese Academy of Sciences. In 40 of the 50 tree shrews, unilateral comminuted fractures of the femur were generated by the impact method. LPS ( $0.5 \mathrm{mg}$, L2880-100MG, lipopolysaccharides from Escherichia coli 055:B5, Sigma) was injected intravenously to create a traumatic systemic inflammatory response syndrome tree shrew model. The other 10 were used as normal controls. Two tree shrews died in the model group 9 days after modeling. All experimental protocols were approved by the Experimental Animal Ethics Committee of the 920th Hospital of Joint Logistics Support Force of PLA. All methods were performed in accordance with the relevant guidelines and regulations.

\section{Body temperature observation and white blood cell count of tree shrews after modeling:}

Ten models and 10 controls were used to measure body temperature 6 times after the model was made. At the same time, white blood cells were counted 4 times before the model, 1 day after the model, 4 days after the model and 10 days after the model.

3. Culture and labeling of umbilical cord mesenchymal stem cells in tree shrews: 
The umbilical cord of the tree shrews was collected by cesarean section, rinsed with salt water, and soaked in double-resistance. The umbilical cord was cut as much as possible with small scissors and placed into a culture bottle for adherent culture. The adherent cells attached for 2-3 days, the DMEM-F12 medium with $20 \%$ fetal bovine serum was changed, and the samples were subcultured until the cells were full. After transfection with the best multiplicity of GFP lentivirus, the optimal concentration of puromycin was added for screening. After changing the solution 3 times, the cell line stably transfected with GFP lentivirus was obtained and photographed under a fluorescence microscope.

\section{Tree shrew grouping and treatment of umbilical cord mesenchymal stem cells:}

After the model was established, 20 tree shrews were given returned UCMSCs through the veins, and 18 tree shrews were not returned with cells as the model control group. The distribution of GFP-positive cells in tissues was observed in frozen sections of 5 tree shrews with UCMSC return at 2 and 10 days, respectively. Twenty days after treatment, 5 tree shrews each were killed in the model group, the normal control group, and the treatment group, and pathological sections were stained with HE to observe the lesions within the model group and the therapeutic effect of the treatment group. The pathological sections of the normal control group were used as normal controls. Ten fields of view were observed within the same tissue, and a representative field of view was taken. Each map had at least 5 similar fields of view as representative fields of view.

\section{Elisa Detection Of Inflammatory Factors In Each Group:}

Before treatment and 1 day, 3 days, and 10 days after treatment, the peripheral blood of 3 tree shrews was collected from the model group, normal control group, and treatment group. The inflammatory factors TNF-a, IL- 6 and IL-10 were detected by ELISA.

\section{Detection of liver function, kidney function and heart function in each group:}

Twenty days after cell treatment, peripheral blood of 5 tree shrews was collected in the model group, normal control group and treatment group to detect liver function, kidney function and heart function.

\section{Statistical Methods:}

Data are expressed as the mean \pm standard deviation, and comparisons between groups were analyzed by one-way ANOVA. Pairwise comparison was conducted using the SNK method. The statistical software used was SPSS 17.0 , and $P<0.05$ was considered statistically significant.

\section{Result}

1. Cultured tree shrew UCMSCs were observed under a light microscope (Figure 1A), and GFP-labeled tree shrew UCMSCs were observed under a fluorescence microscope (Figure 1B).

The cultured tree shrew UCMSCs grew fibrously, were evenly distributed, and grew adherently. The cells were observed with a fluorescence microscope, and the cells were shown to have GFP yellow-green 
fluorescence.

\section{Tree shrew body temperature observation after modeling.}

The body temperature of the tree shrews began to rise one day after the model was made and reached a maximum of 41.3 degrees 10 days after the model was made (Figure 2).

\section{Tree shrew white blood cell count after modeling.}

The tree shrew white blood cell count began to increase 1 day after modeling and reached a maximum of $8.91 \times 10^{9} /$ L 4 days after modeling (Figure 3).

\section{The distribution of fluorescent cells in each organ 2 days after tree shrews were infused with cells.}

Two days after the tree shrew infusion of cells, each organ was frozen and sectioned, and the nuclei were stained with DAPI, which generated blue fluorescence, and the cells imported into the body carried green fluorescence, representing the distribution of transplanted cells. Two days after the infusion of the UCMSCs, the distribution of fluorescent cells in the pancreatic tissue was more obvious. A small number of fluorescent cells were distributed in other tissues (Figure 4).

\section{The distribution of fluorescent cells in each organ 10 days after tree shrews were infused with cells.}

Ten days after the infusion of cells into the tree shrew, the distribution of fluorescent cells in the liver tissue was more obvious. There was a certain amount of fluorescent cell distribution in other tissues (Figure 5).

\section{The distribution of fluorescent cells in each organ in model tree shrews that were not returned with cells.}

The model tree shrew with unreturned cells showed no distribution of fluorescent cells in each tissue (Figure 6).

7. HE staining results in various organs in the model group, treatment group and control group (Figs. 711):

7.1. HE staining of the heart showed that the model group showed more myocardial fiber edema and loose cytoplasmic staining (black arrow), and the treatment group recovered to near the normal level of the control group (Figure 7).

7.2. Liver HE staining showed that there was more hepatocyte edema in the model group, cytoplasmic loose staining (black arrow), a small amount of hepatocyte edema resembling balloon-like degeneration, cell swelling, nuclear centering, and cytoplasmic vacuolization (yellow arrow). A small amount of lymphocyte infiltration (red arrow) was seen around the bile duct in the local portal area. The treatment group returned to near the normal levels of the control group (Figure 8). 
7.3. The spleen HE staining results showed that the spleen nodules in the model group mostly had lymphocyte spotted necrosis, deep stenosis or fragmentation (black arrow). A small amount of extramedullary hematopoietic foci (yellow arrow) was seen in the red pulp. The treatment group returned to near the normal level of the control group (Figure 9).

7.4. HE staining results showed that a large amount of alveolar wall thickening was observed in the model group, accompanied by a large number of lymphocytes and neutrophil infiltration (black arrow), more alveolar wall epithelial cell necrosis, and nuclear fragmentation (yellow arrow). The treatment group returned to near the normal level of the control group (Figure 10).

7.5. Renal HE staining showed that the model group had a small increase in glomerular matrix (black arrow). Renal tubular dilatation was observed in the renal cortex. More lymphocytic focal infiltration was observed in the renal medulla (yellow arrow). The treatment group returned to near the normal level of the control group (Figure 11).

7.6. Intestinal HE staining results showed that the model group showed spot gland necrosis of individual gland cells (black arrow), cytoplasmic vacuolation, and nucleus shrinkage; scattered neutrophils (blue arrow) were seen in the lamina propria. The treatment group returned to close to the normal control group (Figure 12).

7.7. The results of pancreas HE staining showed that some pancreatic islets in the model group showed nucleus contraction (blue arrow) of individual pancreatic islet cells, and the staining was deepened. The treatment group returned to close to the normal control group (Figure 13).

\section{Results of renal PAS and Masson staining in the model group, treatment group and control group (Figure 14):}

Kidney PAS staining of the model group showed more common glomerular basement membrane thickening (black arrow). The treatment group had renal PAS staining. There was no significant thickening of the glomerular basement membrane. Kidney Masson staining of the model group showed a small amount of collagen fiber hyperplasia (black arrow) in the tissue. In the treatment group, kidney Masson staining with no collagen fiber proliferation was observed. The treatment group recovered to near the normal control group.

\section{Test results of inflammatory factors in the model group, normal control group and treatment group:}

9.1. TNF-a test results of the 3 groups:

TNF-a increased in the model group and decreased after treatment (Figure 15).

9.2. IL-6 test results of the 3 groups:

IL-6 increased in the model group and decreased after treatment (Figure 16). 
9.3. IL-10 test results of the 3 groups:

IL-10 decreased in the model group and increased after treatment (Figure 17).

\section{Results of liver function, renal function and heart function tests in the model group, normal control group and treatment group:}

10.1 Results of renal function tests in the three groups (Figure 18): Urea and creatinine in the model group were significantly increased and were significantly reduced after treatment.

10.2 Results of liver function tests in the three groups (Figure 19): The model group had significant increases in alanine aminotransferase and aspartate aminotransferase, which were significantly reduced after treatment.

10.3 Results of heart function tests in the three groups (Figure 20): The creatine kinase and phosphocreatine kinase isoenzymes in the model group were significantly increased and were significantly reduced after treatment.

\section{Discussion:}

"Injury" is an important cause of the reduction in troops and the weakening of the combat effectiveness of troops. Therefore, research on the prevention and treatment of war wounds has always been a core focus in the field of military medicine and has been highly valued by the military of various countries [12]. Since decisive battles of most military conflicts in the future will occur in densely populated cities, this will lead to an increase in war damage. Compared with other war wounds, urban war wounds are characterized by large numbers of wounded people and complex injury types and injury classes. Detonation injury, crush injury, multiple injuries, burns, etc., are significantly increased $[13,14]$.

In modern local wars, various explosive weapons are still the main strategic and tactical weapons. They have large explosive power, produce shrapnel, and can be fanned or stereoscopically projected [3]. The killing area is large, and the targets are accurate. The killing effect of modern weapons has the characteristics of high speed, high efficiency, high intensity, and soft killing (three highs and one soft). These characteristics will cause serious injury consequences, mainly manifested as more serious wounds, a greater number of wounds, more burns and multiple injuries. Psychological barriers and physiological imbalances lead to a high attrition rate, high shock rate, and high surgical rate (four more three highs). This causes complicated modern war wounds, damages more troops, causes a large trauma area, and makes early complications more dangerous. Because of the long time that can elapse after an early injury, late complications can increase, making the rescue process more difficult $[15,16]$. Among various war wounds, firearm injuries caused by high-speed low-quality weapons represent the highest proportion of war wounds in modern local warfare. The characteristics of the injuries are extensive, and serious tissue damage, multiple injuries and multiple injuries are increased. Complicated wounds and serious infection can occur $[17,18]$. In the study of the damage associated with vital organs, it was found 
that after injury from a high-speed steel ball to the maxillofacial region, the animal's heart, lung and other important organs showed a small amount of flaky bleeding. If an infection occurred after injury, shock, etc., the conditions and pathological basis were conducive to the occurrence and development of serious complications such as acute respiratory distress syndrome, disseminated intravascular coagulation, or multiple organ failure [19-22]. This series of posttraumatic syndromes is an important cause of the high death rate. Rapid and effective control and treatment of posttraumatic syndrome is a hot topic at home and abroad. Therefore, the establishment of repeatable animal models for combative traumatic infection, systemic inflammatory response syndrome, shock, multiple organ failure, and new treatments based on this animal model have significant military and scientific significance.

We used the impact method to make a unilateral femoral comminuted fracture and then injected LPS into the traumatic systemic inflammatory response syndrome tree shrew model. GFP-labeled umbilical cord mesenchymal stem cells were used for transplantation. Two and ten days after transplantation, sections were taken and observed by fluorescence microscopy. GFP-labeled cells were observed in each tissue, and liver tissue was observed 10 days after transplantation. The distribution of GFP-positive cells was high, indicating that the liver has to deal with a large number of foreign cells. In the model group of untransplanted cells, no fluorescence cell distribution was observed in any organ tissue. Twenty days after cell treatment, $\mathrm{HE}$ staining results of the organs of the three groups showed that there were some lesions in the tissues of the model group, and the treatment group recovered to near the normal control group. In the model group, PAS staining of the kidney showed more thickening of the glomerular basement membrane. The PAS staining of the kidney in the treatment group and the glomerular basement membrane showed no obvious thickening and recovered to near the normal level of the control. The model group was stained with Masson staining, and a small amount of collagen fibers was found in the tissue. In the treatment group, Masson staining of the kidney showed no collagen fibrosis and recovery to near the normal level of the control.

According to the HE staining results, the establishment of the model of traumatic systemic inflammatory response syndrome in tree shrews was successful. After treatment with umbilical cord mesenchymal stem cells, the indicators of the treatment group tended to improve, indicating that umbilical cord mesenchymal stem cells have roles in treatment. Ten days after cell transplantation in the tree shrew systemic inflammatory response syndrome model, most of the cells were distributed in the liver, and other organs also had a certain distribution that played a role in the tissue so that the damage was restored. The results of liver function, renal function and heart function tests in the model group, normal control group and treatment group showed that the organ functions of the model group were significantly increased and decreased significantly after treatment. These results all indicate that the creation of the model was successful and that the treatment with umbilical cord mesenchymal stem cells was effective because all lesions in the treatment group tended to return to the level of the normal control group.

\section{Declarations}




\section{- Ethics approval and consent to participate}

All experimental protocols were approved by the Experimental Animal Ethics Committee of the 920th Hospital of Joint Logistics Support Force of PLA. All methods were performed in accordance with the relevant guidelines and regulations.

\section{- Consent for publication}

All the authors are consent for publication of the paper.

\section{- Availability of data and material}

All the data and material are available in the paper.

\section{- Competing interests}

The authors declare that they have no competing interest.

\section{- Funding}

This work was supported by grants from the Yunnan Science and Technology Plan Project Major Science and Technology Project (2018ZF007), the Yunnan Province Key Projects (2018FA041, 2017FA040), The whole army experimental animal special (SYDW (2016) 004), and the 920th Hospital of the PLA Joint Logistics Support Force In-hospital technology plan (2019YGB17, 2019YGA05).

\section{- Acknowledgements}

We thank American Journal Experts for assisting with the preparation of this manuscript.

Authors' contributions

MYLG, XMC, GPR and XY made substantial contributions to study conception and design, data acquisition, or data analysis and interpretation.

ZAL and RQP agree to be accountable for all aspects of the work and ensure that questions related to the accuracy or integrity of any part of the work will be appropriately investigated and resolved.

XHP and GPR have given final approval of this version of the manuscript for publication.

GPR, XHP, JXW, XY and RQP have been involved in drafting the manuscript or revising it critically for important intellectual content.

All authors read and approved the final manuscript. 
Author contribution statement

Guang-ping RUAN and Xiang YAO wrote the main manuscript text, and Mi-yang Liu-Gao, Jin-xiang Wang and Xue-min CAl prepared Figures 1-10. Zi-an Li, Rong-qing PANG and Xing-hua PAN prepared Figures 1120.

\section{References}

1. Anderson, S.L. and B. Singh.(2017). Neutrophil apoptosis is delayed in an equine model of colitis: Implications for the development of systemic inflammatory response syndrome. Equine Vet $\mathrm{J} 49$, 383-388.

2. Garcia-Lamberechts, E.J., F.J. Martin-Sanchez, A. Julian-Jimenez, F. Llopis, M. Martinez-Ortiz de Zarate, M.J. Arranz-Nieto, F. Gonzalez-Martinez, P. Pinera Salmeron, C. Navarro-Bustos, and J. Gonzalez-Del Castillo.(2018). Infection and systemic inflammatory response syndrome in older patients in the emergency department: a 30-day risk model. Emergencias 30, 241-246.

3. Li, T., X.Z. Sun, D.H. Lai, X. Li, and Y.Z. He.(2018). Fever and systemic inflammatory response syndrome after retrograde intrarenal surgery: Risk factors and predictive model. Kaohsiung $\mathrm{J}$ Med Sci 34, 400-408.

4. Mahassadi, A.K., J.L.K. Nguieguia, H.Y. Kissi, A.A. Awuah, A.D. Bangoura, S.A. Doffou, and A.K. Attia. (2018). Systemic inflammatory response syndrome and model for end-stage liver disease score accurately predict the in-hospital mortality of black African patients with decompensated cirrhosis at initial hospitalization: a retrospective cohort study. Clin Exp Gastroenterol 11, 143-152.

5. Cao, J., E.B. Yang, J.J. Su, Y. Li, and P. Chow.(2003). The tree shrews: adjuncts and alternatives to primates as models for biomedical research. J Med Primatol 32, 123-130.

6. Fan, Y., Z.Y. Huang, C.C. Cao, C.S. Chen, Y.X. Chen, D.D. Fan, J. He, H.L. Hou, L. Hu, X.T. Hu, et al. (2013). Genome of the Chinese tree shrew. Nat Commun 4, 1426.

7. Li, R., W. Xu, Z. Wang, B. Liang, J.R. Wu, and R. Zeng.(2012). Proteomic characteristics of the liver and skeletal muscle in the Chinese tree shrew (Tupaia belangeri chinensis). Protein Cell 3, 691-700.

8. Fang, S., C. Xu, Y. Zhang, C. Xue, C. Yang, H. Bi, X. Qian, M. Wu, K. Ji, Y. Zhao, et al.(2016). Umbilical Cord-Derived Mesenchymal Stem Cell-Derived Exosomal MicroRNAs Suppress Myofibroblast Differentiation by Inhibiting the Transforming Growth Factor-beta/SMAD2 Pathway During Wound Healing. Stem Cells Transl Med 5, 1425-1439.

9. Wagner, R., P. Piler, B. Uchytil, R. Halouzka, H. Kovaru, M. Bobkova, and P. Nemec.(2016). Systemic inflammatory response syndrome is reduced by preoperative plasma-thrombo-leukocyte aphaeresis in a pig model of cardiopulmonary bypass. Biomed Pap Med Fac Univ Palacky Olomouc Czech Repub 160, 399-406.

10. Ward, L., M. Paul, and S. Andreassen.(2017). Automatic learning of mortality in a CPN model of the systemic inflammatory response syndrome. Math Biosci 284, 12-20. 
11. Xu, R.(2019). Combination of Systemic Inflammatory Response Syndrome and Quick-SOFA: Is This a New Vital Model to Initiate or Escalate Therapy in Patients With Sepsis? Chest 155, 243-244.

12. Scap, M. and S. Kalenic.(1991). [Prevention of wound infection in craniocerebral war injuries]. Lijec Vjesn 113, 289.

13. Xu, T., M.Y. Shen, X.G. Wang, C.D. Qu, and F.C. Lu.(2019). [Treatment and nursing of one patient with burns on perineal region and complicated by secondary multiple organ injuries by exposing to paraquat fluid]. Zhonghua Shao Shang Za Zhi 35, 546- 547.

14. Scepi, M.(2007). [Evaluation of the severity and extent of early complications in burns, multiple trauma, abdominal injuries, craniofacial injuries, injuries of the extremities, thoracic injuries, preceding injuries of soft tissues. Part 4-preceding injuries of soft tissues]. Rev Prat 57, 337-343.

15. Klausner, J.M. and R.R. Rozin.(1995). Late abdominal complications in war wounded. J Trauma 38, 313-317.

16. Hadziahmetovic, Z.(1995). [The effect of organization of treatment of injuries on the occurrence of late complications of fractures caused by gunshots and explosions in war]. Med Arh 49, 83-86.

17. Yee, M.K., P.A. Janulewicz, D.R. Seichepine, K.A. Sullivan, S.P. Proctor, and M.H. Krengel.(2017). Multiple Mild Traumatic Brain Injuries Are Associated with Increased Rates of Health Symptoms and Gulf War Illness in a Cohort of 1990-1991 Gulf War Veterans. Brain Sci 7.

18. Patzkowski, J.C., J.A. Blair, A.J. Schoenfeld, R.A. Lehman, and J.R. Hsu.(2012). Multiple associated injuries are common with spine fractures during war. Spine J 12, 791-797.

19. Huang, P.M., T.H. Lin, P.R. Tsai, and W.J. Ko.(2013). Intrapleural steroid instillation for multiple organ failure with acute respiratory distress syndrome. Shock 40, 392-397.

20. Lee, B.J., C.Y. Chen, S.Y. Hu, Y.T. Tsan, T.C. Lin, and L.M. Wang.(2011). Otalgia and eschar in the external auditory canal in scrub typhus complicated by acute respiratory distress syndrome and multiple organ failure. BMC Infect Dis 11, 79.

21. Del Sorbo, L. and A.S. Slutsky.(2011). Acute respiratory distress syndrome and multiple organ failure. Curr Opin Crit Care 17, 1-6.

22. Lyons, W.S.(2010). Fresh frozen plasma is not independently associated with a higher risk of multiple organ failure and acute respiratory distress syndrome. J Trauma 68, 749.

\section{Figures}




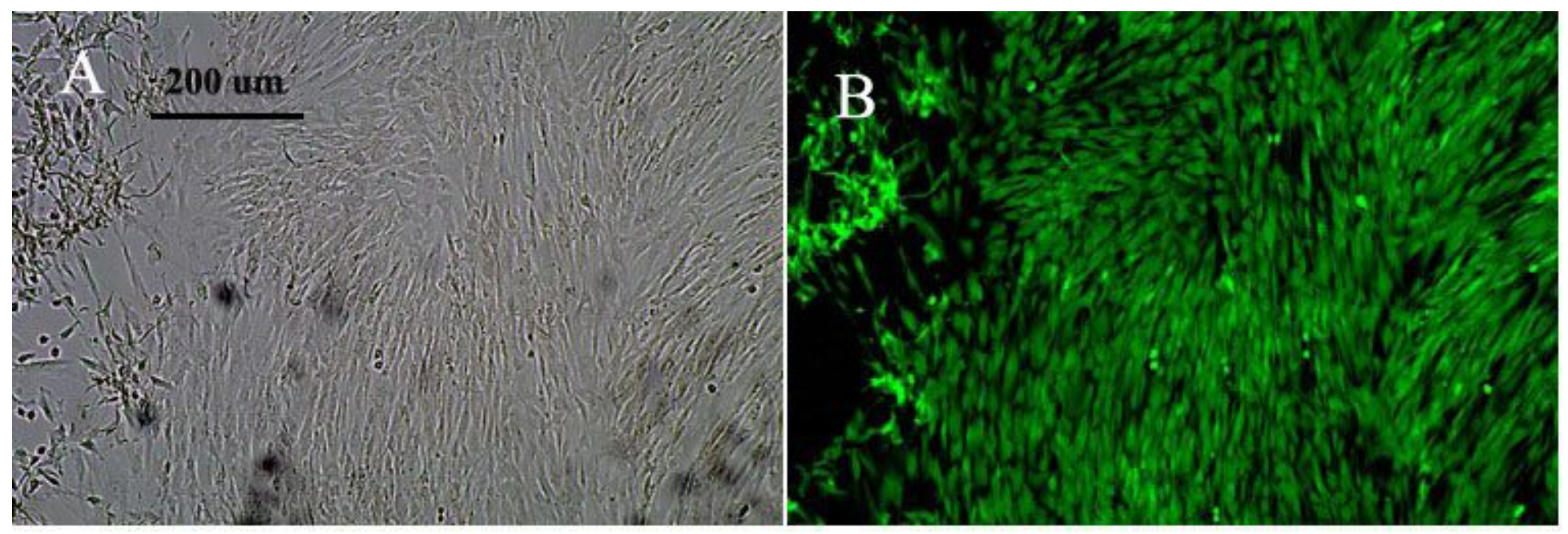

Figure 1

Morphology of tree shrew UCMSCs and GFP labeling. A: Tree shrew UCMSCs cultured under a light microscope grew fibrously adherent. B: GFP-labeled tree shrew UCMSCs with yellow-green fluorescence.

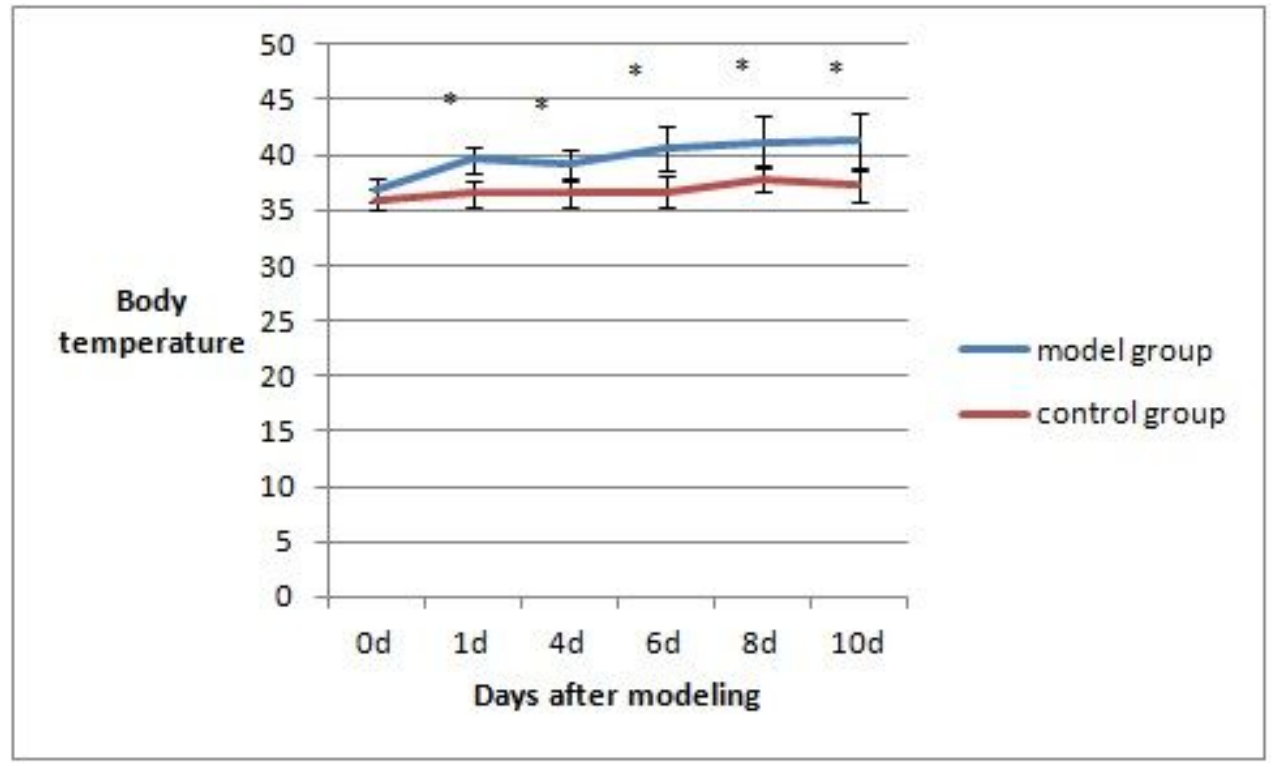

Figure 2

Body temperature observation of tree shrews after modeling $(n=10)$. * Indicates $P<0.05$. 


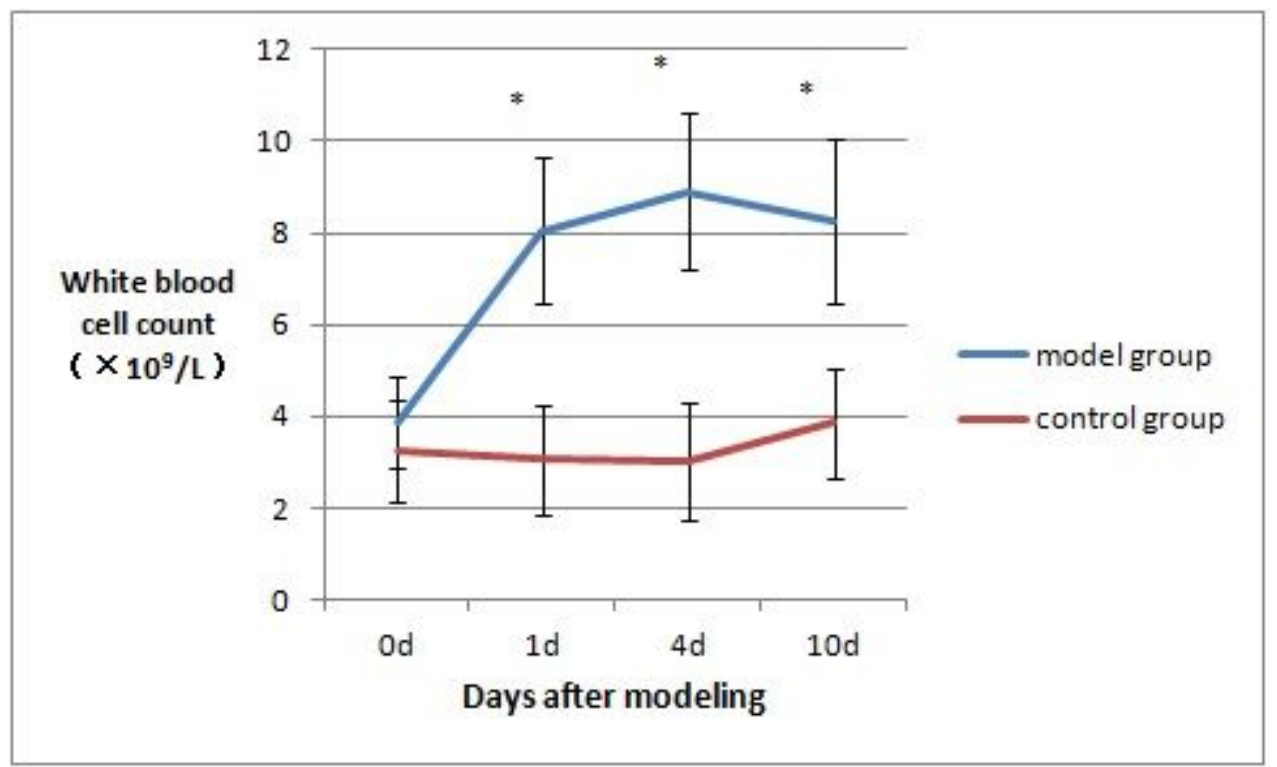

\section{Figure 3}

White blood cell count of tree shrews after modeling $(n=10) .{ }^{*}$ Indicates $P<0.05$. 


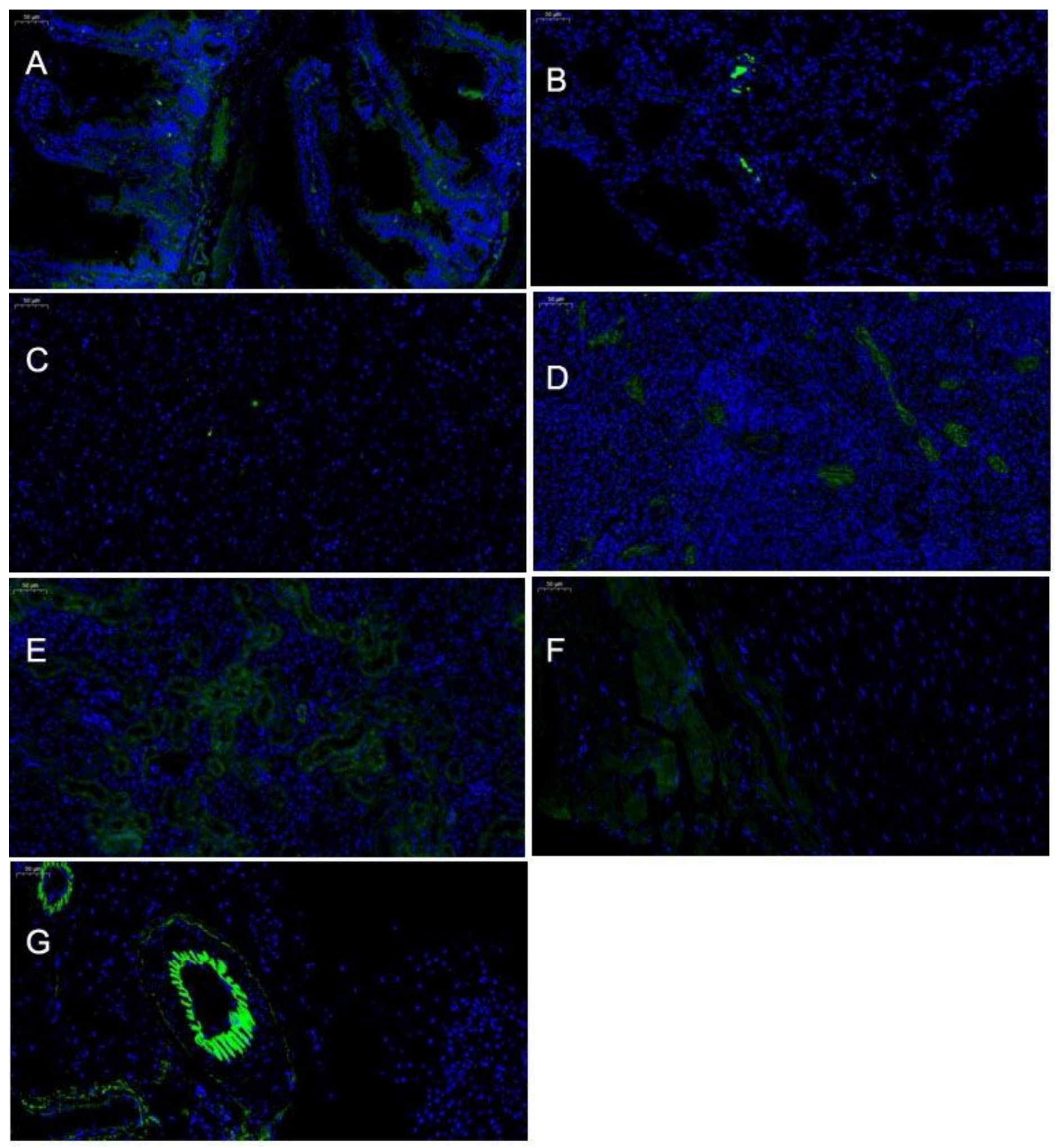

\section{Figure 4}

The distribution of fluorescent cells (200-fold) in each organ two days after infusion of GFP-labeled cells. A: Distribution of fluorescent cells in intestinal tissue. B: Distribution of fluorescent cells in lung tissue. C: Distribution of fluorescent cells in liver tissue. D: Distribution of fluorescent cells in spleen tissue. E: Distribution of fluorescent cells in renal tissue. F: Distribution of fluorescent cells in cardiac tissue. G: 
Distribution of fluorescent cells in pancreatic tissue. Two days after the infusion of UCMSCs, the distribution of fluorescent cells in the pancreatic tissue was more obvious.

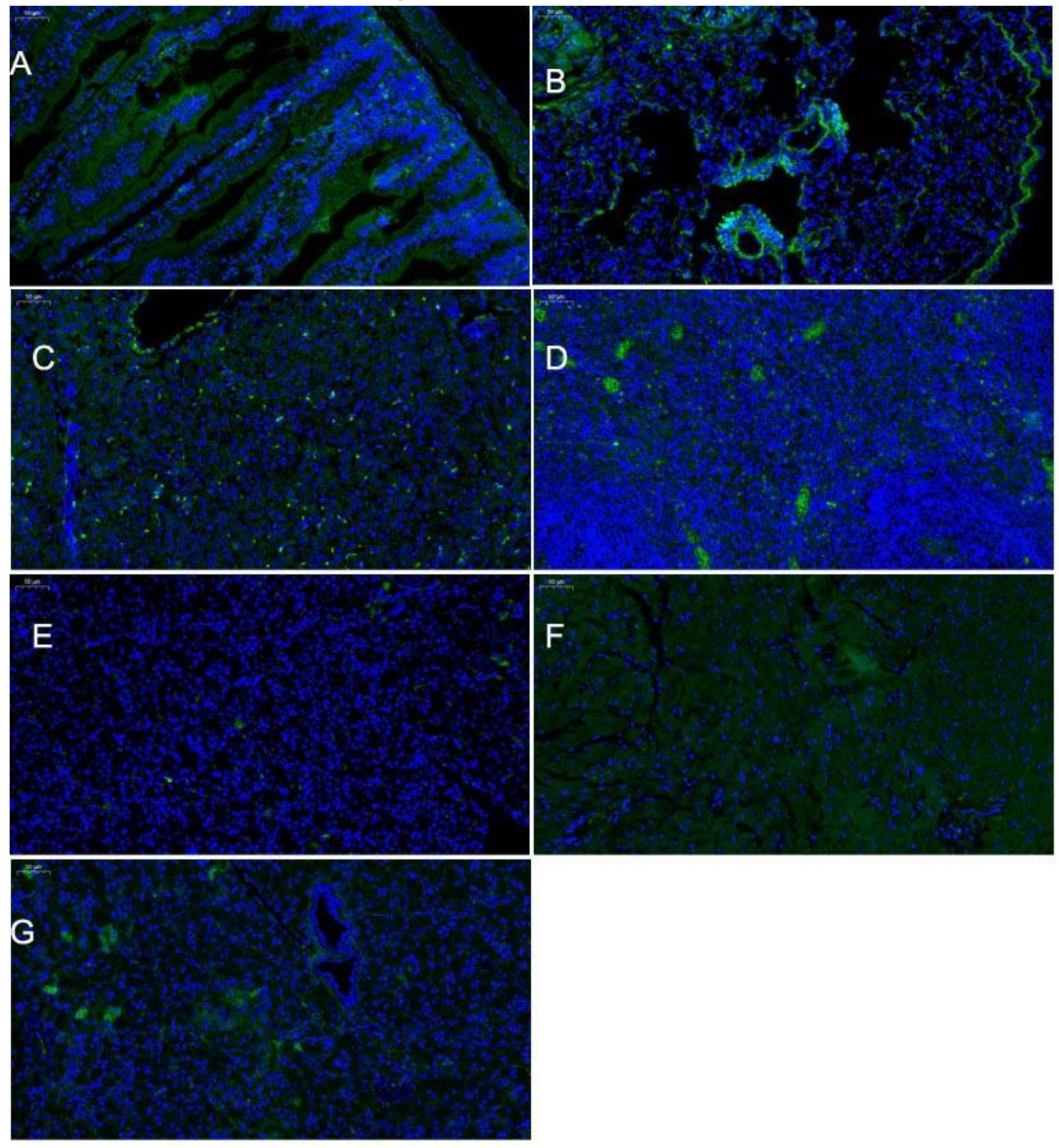

\section{Figure 5}

The distribution of fluorescent cells (200-fold) in each organ 10 days after infusion of GFP-labeled cells. A: Distribution of fluorescent cells in intestinal tissue. B: Distribution of fluorescent cells in lung tissue. C: Distribution of fluorescent cells in liver tissue. D: Distribution of fluorescent cells in spleen tissue. E: 
Distribution of fluorescent cells in renal tissue. F: Distribution of fluorescent cells in cardiac tissue. G: Distribution of fluorescent cells in pancreatic tissue. Ten days after the infusion of the tree shrew, the distribution of fluorescent cells in the liver tissue was more obvious.

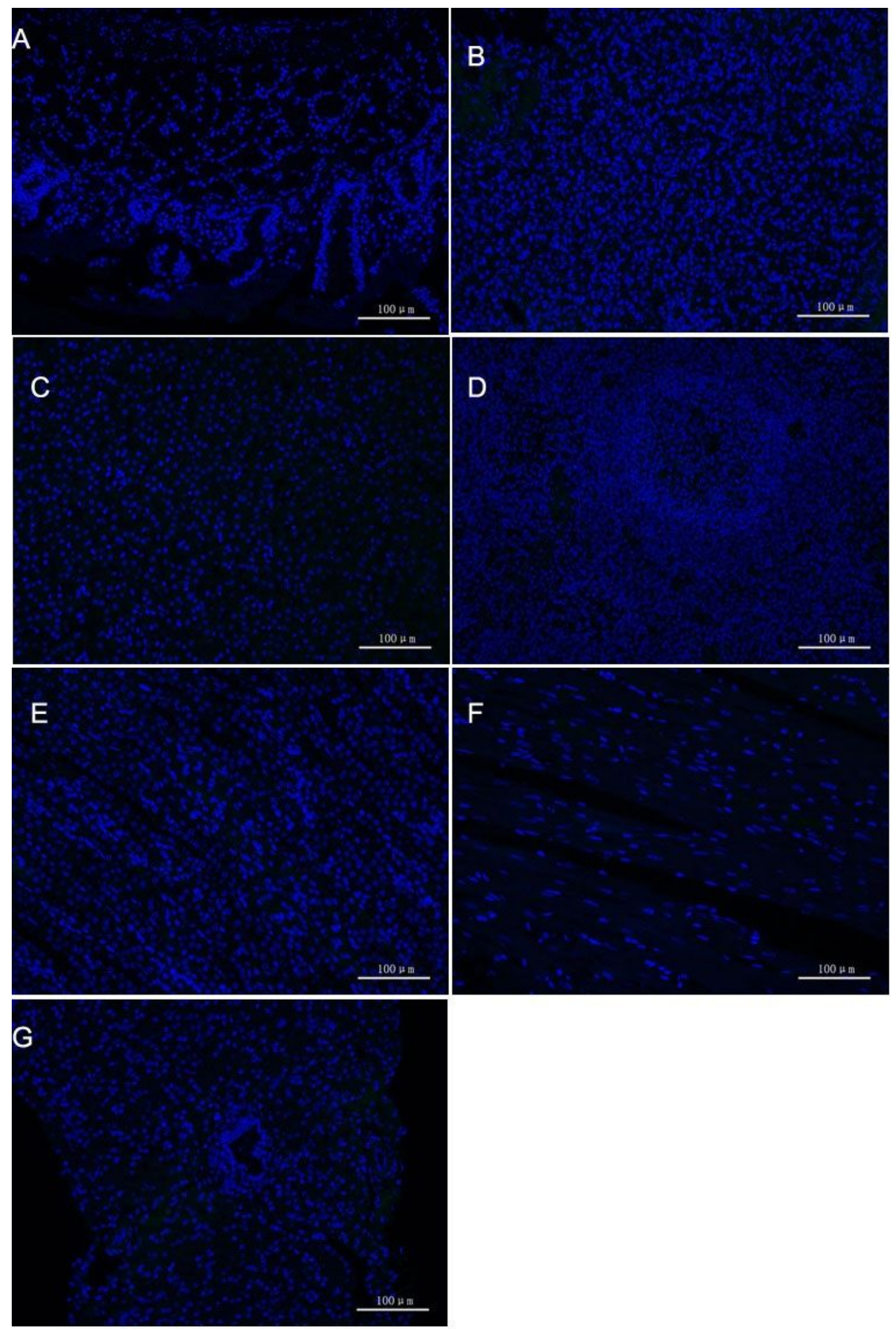

\section{Figure 6}

The distribution of fluorescent cells in each organ of the model tree shrew without the return of cells (200 times). A: Intestinal tissue was observed under a fluorescence microscope. B: The lung tissue was 
observed under a fluorescence microscope. C: The liver tissue was observed under a fluorescence microscope. D: The spleen was observed under a fluorescence microscope. E: The kidney was observed under a fluorescence microscope. F: The heart was observed under a fluorescence microscope. G: The pancreatic tissue was observed under a fluorescence microscope. The model tree shrew without the return of cells showed no distribution of fluorescent cells in each tissue.
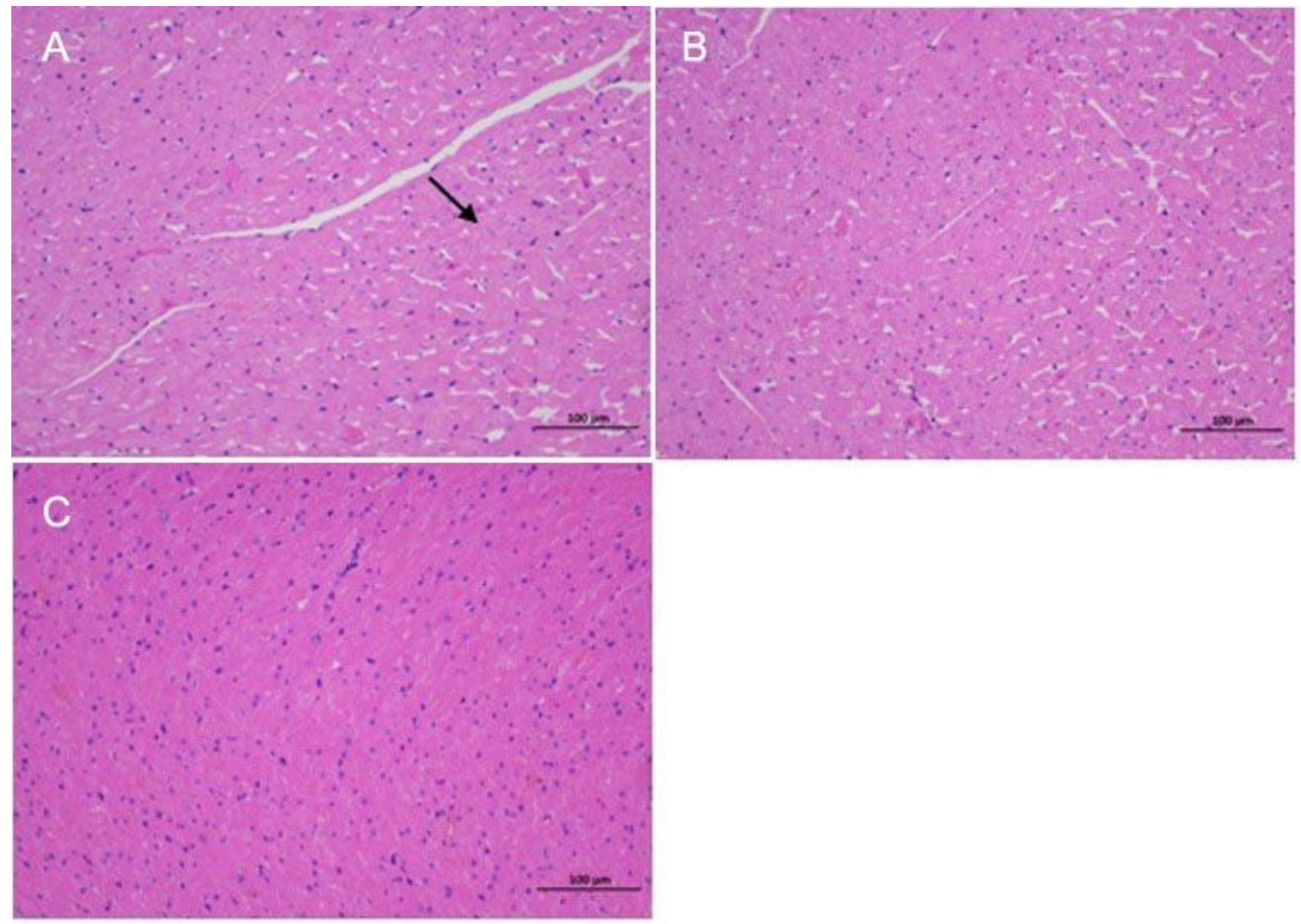

\section{Figure 7}

The results of cardiac HE staining. A: The model group was HE stained. More myocardial fiber edema was seen in the tissue and cytoplasmic loose staining (black arrow) B: HE staining of the treatment group. There was no obvious abnormality in the interstitium, and no obvious inflammation was observed. C: HE staining of the control group. The tissue staining was uniform, the myocardial fiber morphology was normal, the arrangement was regular, the boundary was clear, the interstitium was not obvious, and no obvious inflammation was observed. 

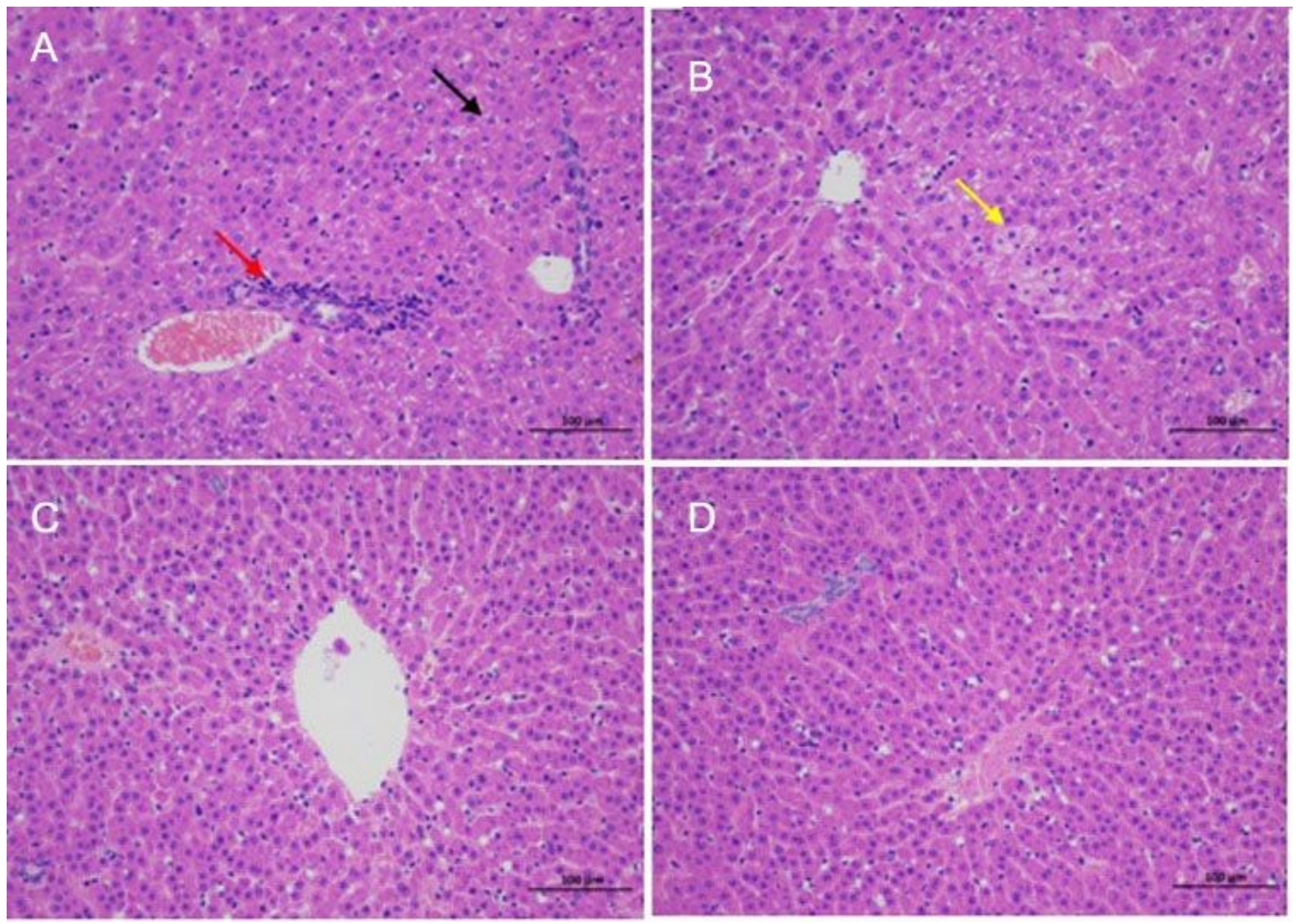

\section{Figure 8}

The results of liver HE staining. A and B: Liver HE staining. Locally, more hepatocyte edema, cytoplasmic loose staining (black arrow), a small amount of hepatocyte edema resembling balloon-like degeneration, cell swelling, nuclear centering, cytoplasmic vacuolization (yellow arrow), and a local small area around the bile duct lymphocyte infiltration were observed (red arrow). C: Hepatic HE staining in the treatment group. The structure of the hepatic lobule is clear, and the hepatic cords are arranged neatly. D: Liver HE staining of the control group. The structure of the hepatic lobule was clear, the hepatic cord was neatly arranged, the cytoplasm of the hepatocytes was abundant, the morphological structure was normal, the hepatic sinus was not significantly dilated or squeezed, and no obvious inflammation was observed. 

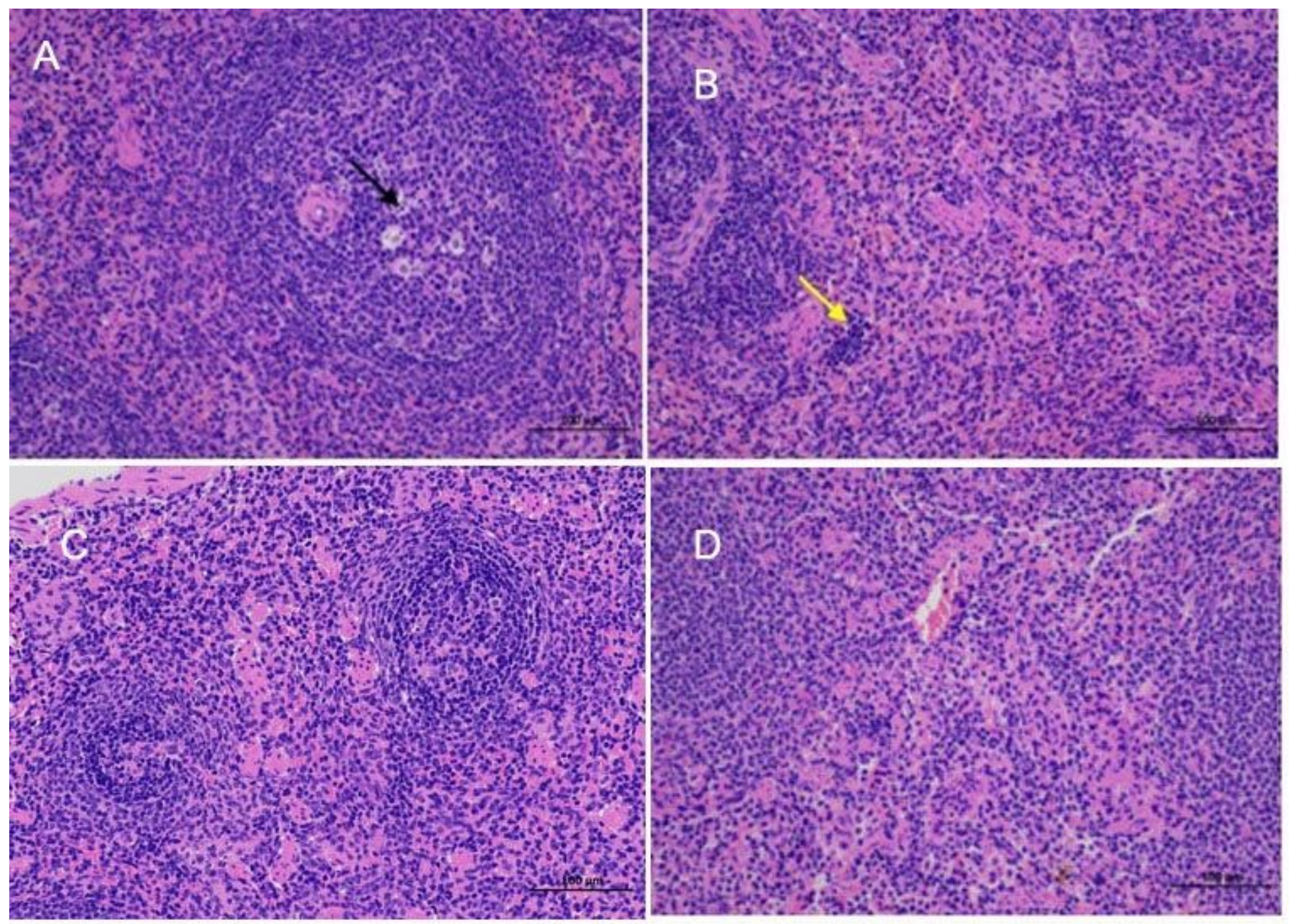

\section{Figure 9}

Spleen HE staining results. A and B: Spleen HE staining of the model groups. The red pulp/white pulp boundary is clear, lymphoid punctate necrosis is often seen in the spleen nodules, nuclear pyknosis is deeply stained or fragmented (black arrow), and a small amount of extramedullary hematopoietic foci (yellow arrow) is seen in the red pulp. C: Spleen HE staining of the treatment group. The treatment group returned to near normal of the control. D: Spleen HE staining of the control group. No obvious abnormalities were found in the red pulp. 

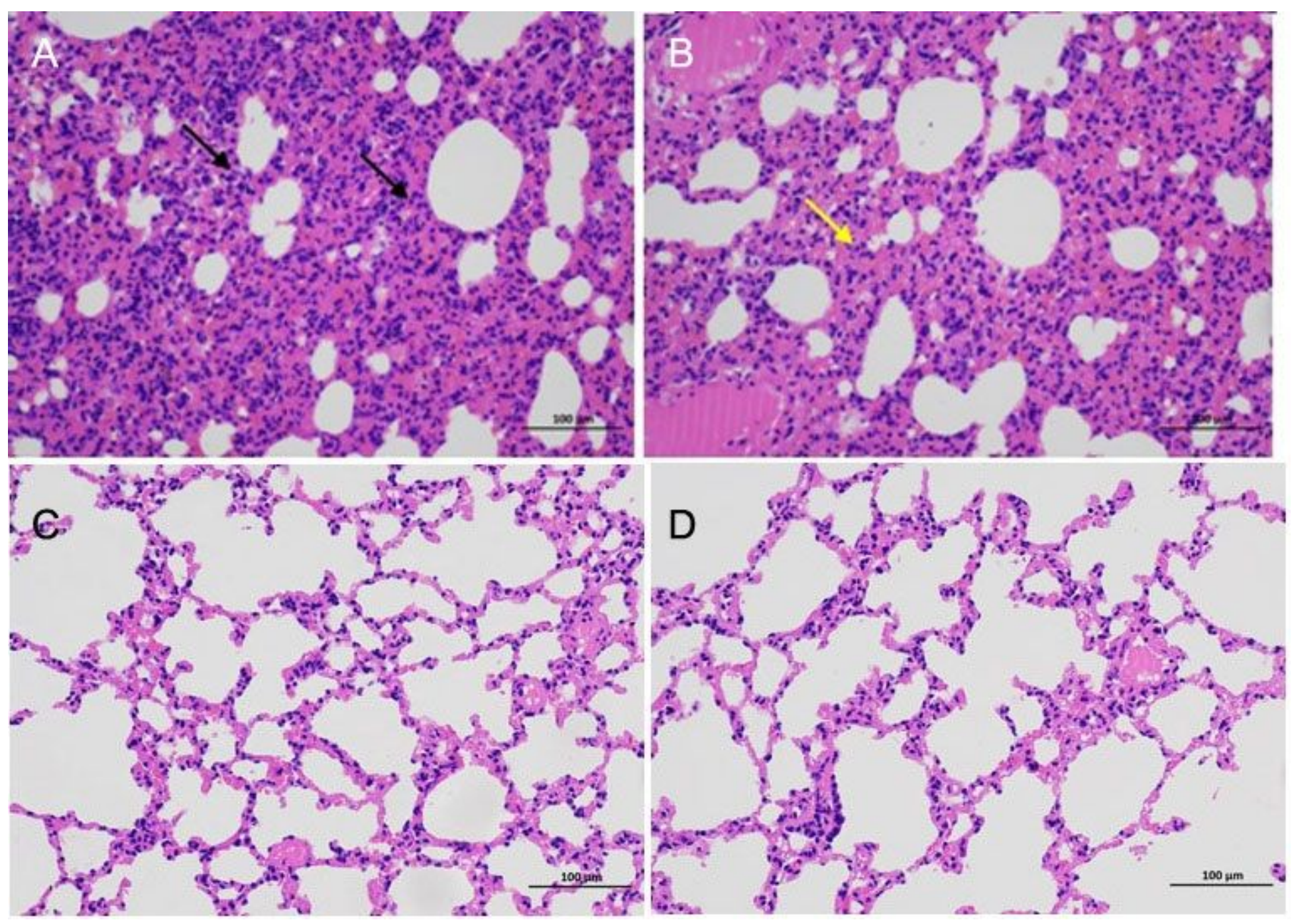

Figure 10

The results of lung HE staining. A and B: HE staining of lungs in the model group. A large number of alveolar wall thickenings was observed in the tissue, accompanied by a large number of lymphocytes and neutrophil infiltration (black arrow); more alveolar wall epithelial cell necrosis and nuclear fragmentation (yellow arrow) were observed locally. C: HE staining of the lungs in the treatment group. No obvious abnormalities were observed. D: Lung HE staining of the control group. No obvious abnormalities were observed. 

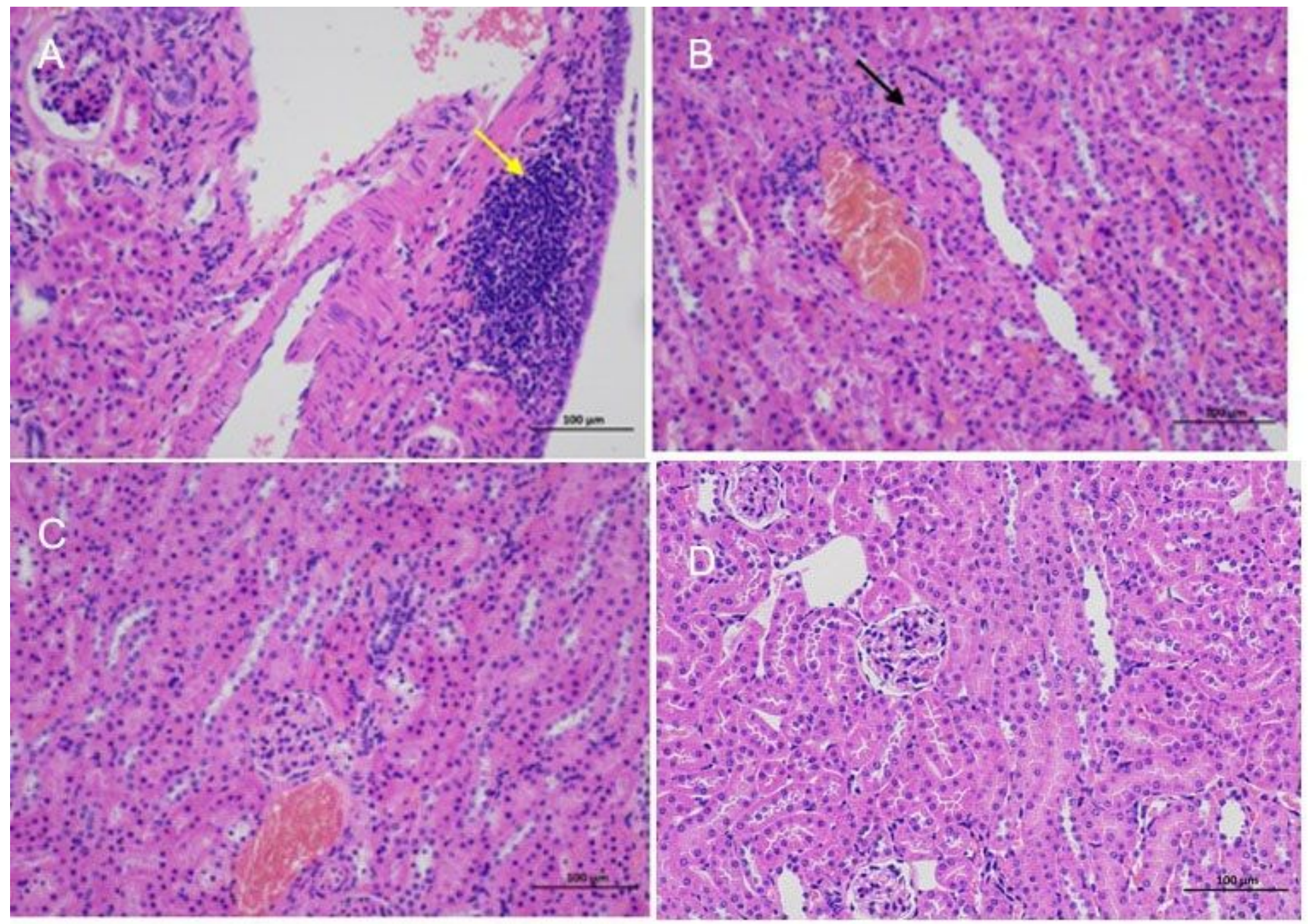

\section{Figure 11}

The results of kidney HE staining. A and B: Renal HE staining of the model groups. More common glomerular matrix increased (black arrow). Renal tubular dilatation can be seen in the renal cortex. Renal lymphocytes focally infiltrated (yellow arrow). C: HE staining of kidneys in the treatment group. The tissue staining was uniform, the renal cortex medulla was clearly defined, the glomerular morphological structure was normal, and the renal tubular epithelial cells were closely arranged. D: Kidney HE staining in the control group. No obvious abnormalities were observed. 

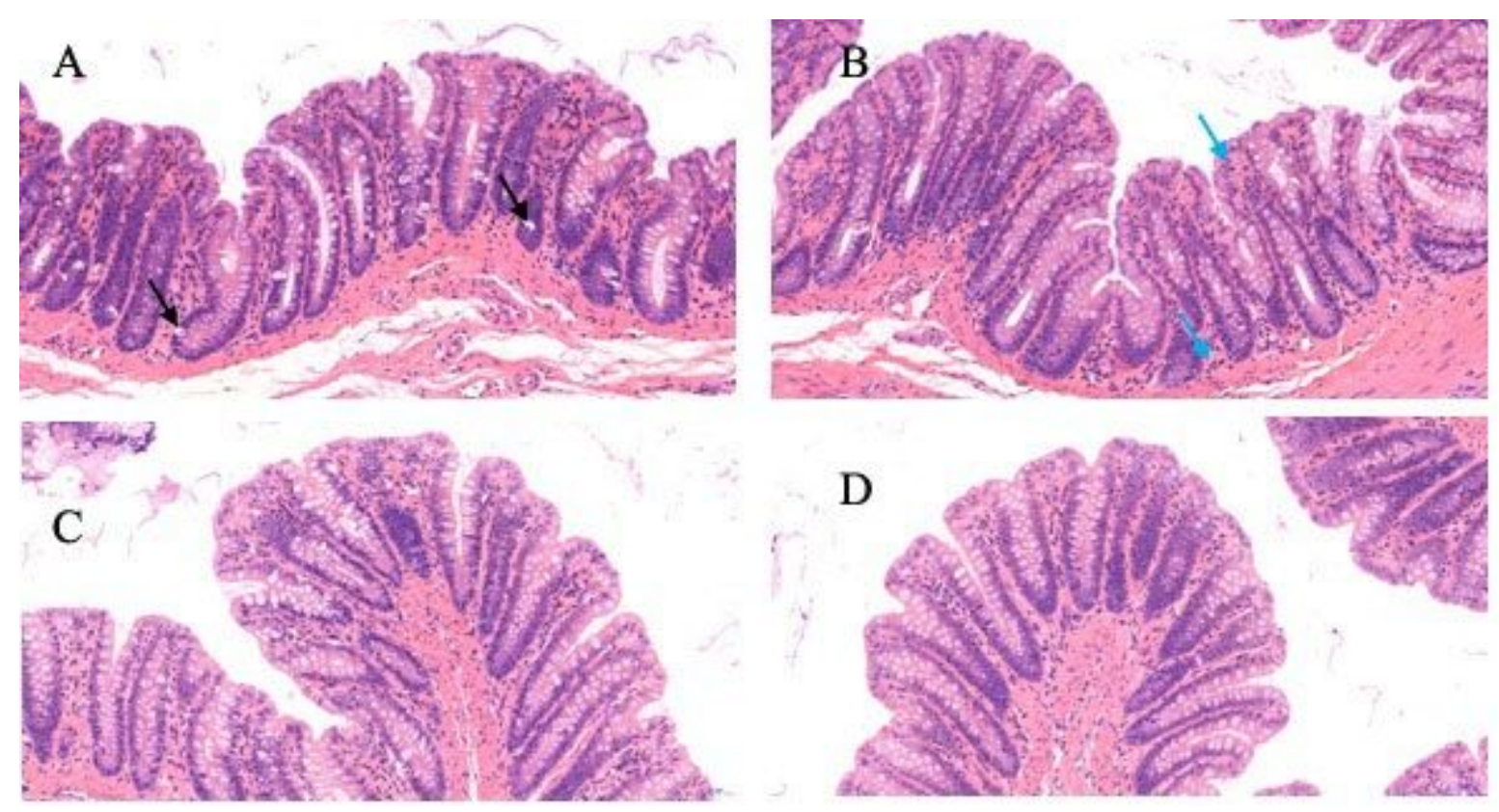

Figure 12

Results of intestinal HE staining. A and B: Model group intestinal HE staining. Spotted necrosis of individual glandular cells (black arrow), vacuolation of cytoplasm, and shrinkage of nuclei are observed; scattered neutrophils (blue arrow) are present in the lamina propria. C: Intestinal HE staining in the treatment group. The tissue mucosa epithelium was intact, no obvious necrosis or shedding was observed; the number of glands was abundant, a large number of goblet cells was seen, and there was no obvious abnormality in morphology; D: Control group intestinal HE staining. No obvious abnormalities were observed.
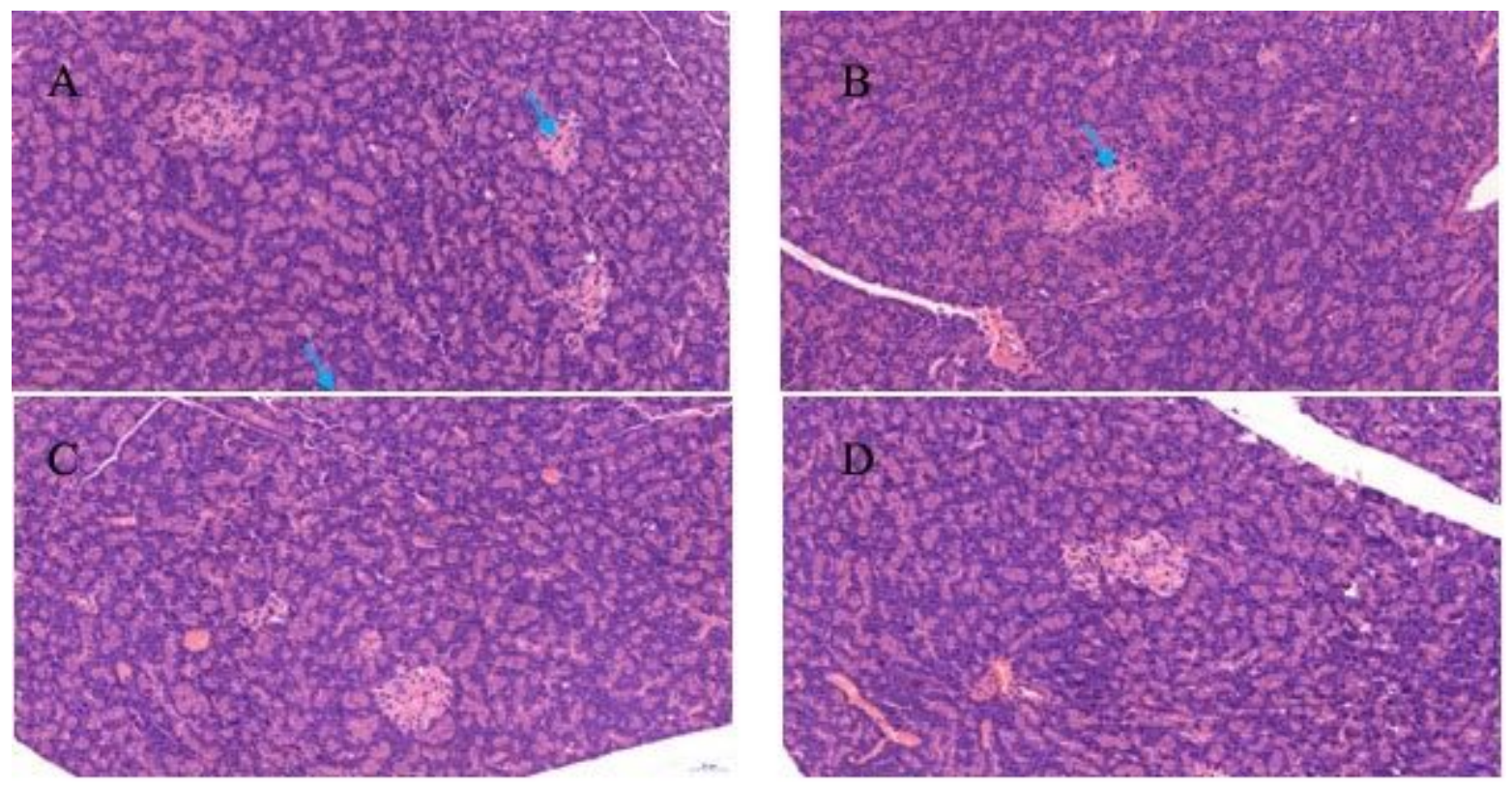

Figure 13 
Results of pancreas HE staining. A and B: HE staining of the pancreas in the model groups. It can be seen that the nucleus of individual islet cells is contracted (blue arrow), and the staining is deepened. C: Pancreas HE staining in treatment group. There are many islets in the tissue, and there is no obvious abnormality in the morphological structure; there is no obvious abnormality in the morphological structure of the pancreatic exocrine acinar. D: Control group pancreas HE staining. No obvious abnormalities were observed.

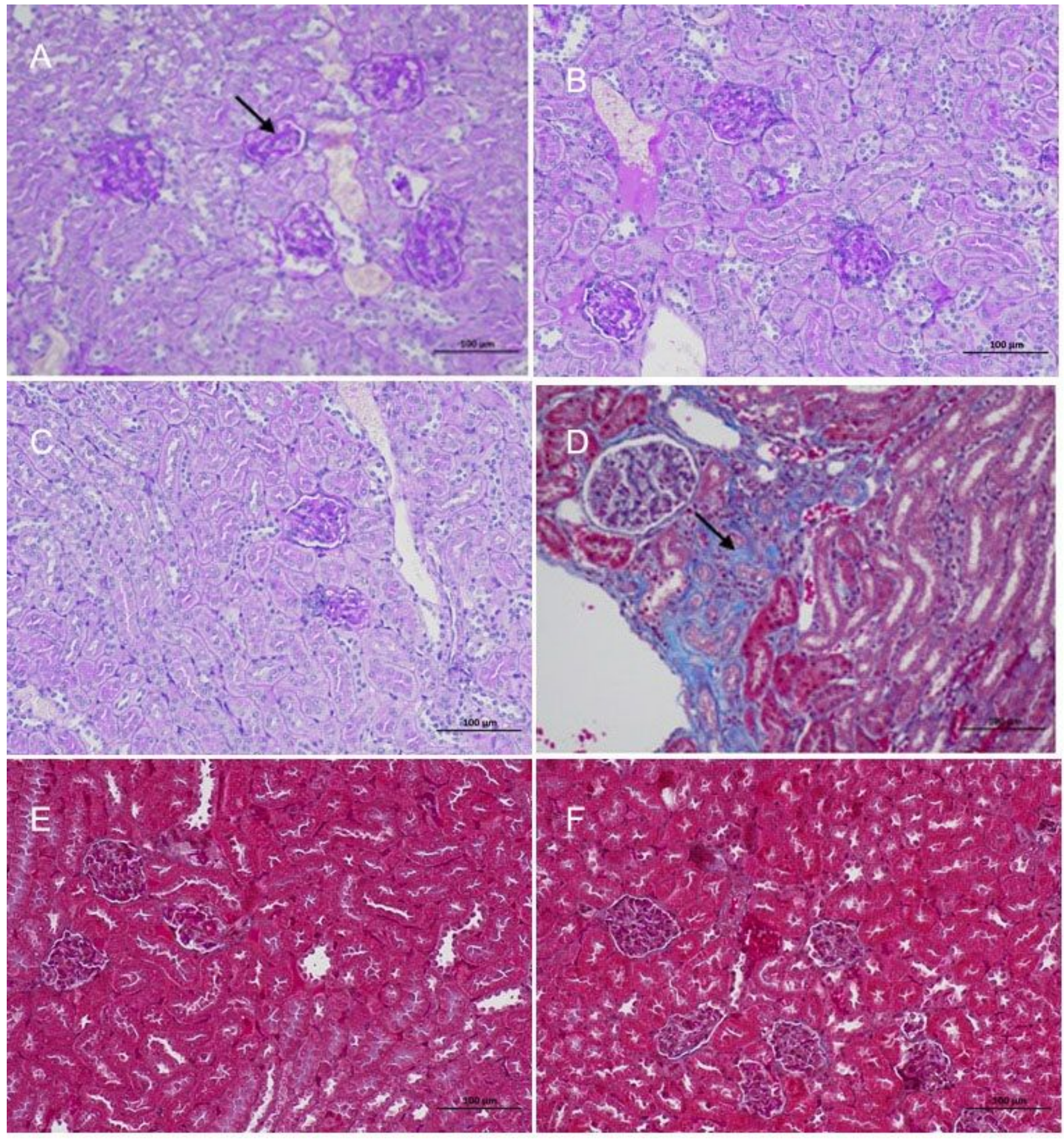

Figure 14 
The results of kidney PAS and Masson staining. A: Model group kidney PAS staining showed more common glomerular basement membrane thickening (black arrow). B: Kidney PAS staining in the treatment group with no significant thickening of the glomerular basement membrane. C: Control group kidney PAS staining showed that there was no significant thickening of the glomerular basement membrane. D: Model group kidney Masson staining. A small amount of collagen fiber hyperplasia (black arrow) is seen in the tissue. E: Kidney Masson staining of the treatment group where no collagen fiber proliferation was observed. F: Kidney Masson staining of the control group where no collagen fiber proliferation was observed.

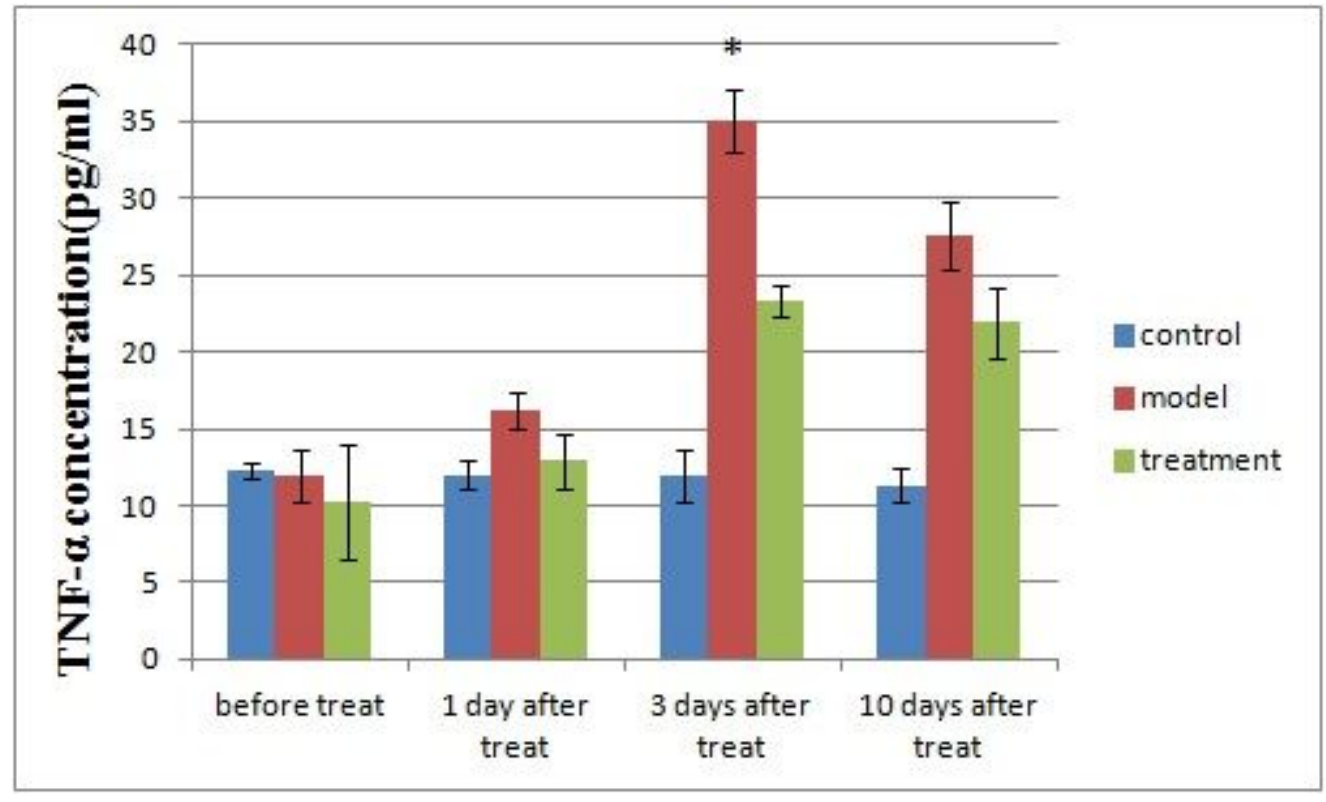

\section{Figure 15}

Results of TNF-a detection by ELISA. The results are shown as the mean \pm standard deviation $(n=3)$. * $P$ $<0.01$, compared with the control group.

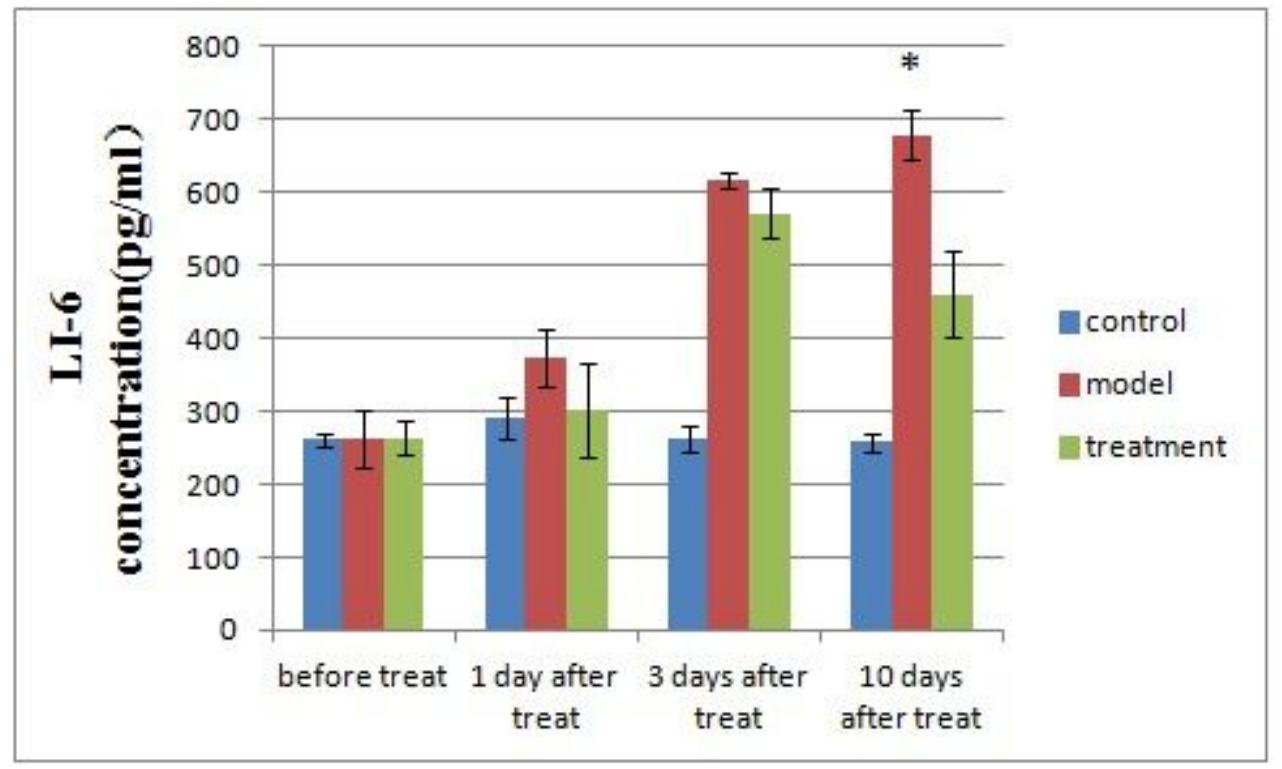

Figure 16 
Results of IL- 6 detection by ELISA. The results are shown as the mean \pm standard deviation $(n=3)$. * $P$ $<0.01$, compared with the control group.

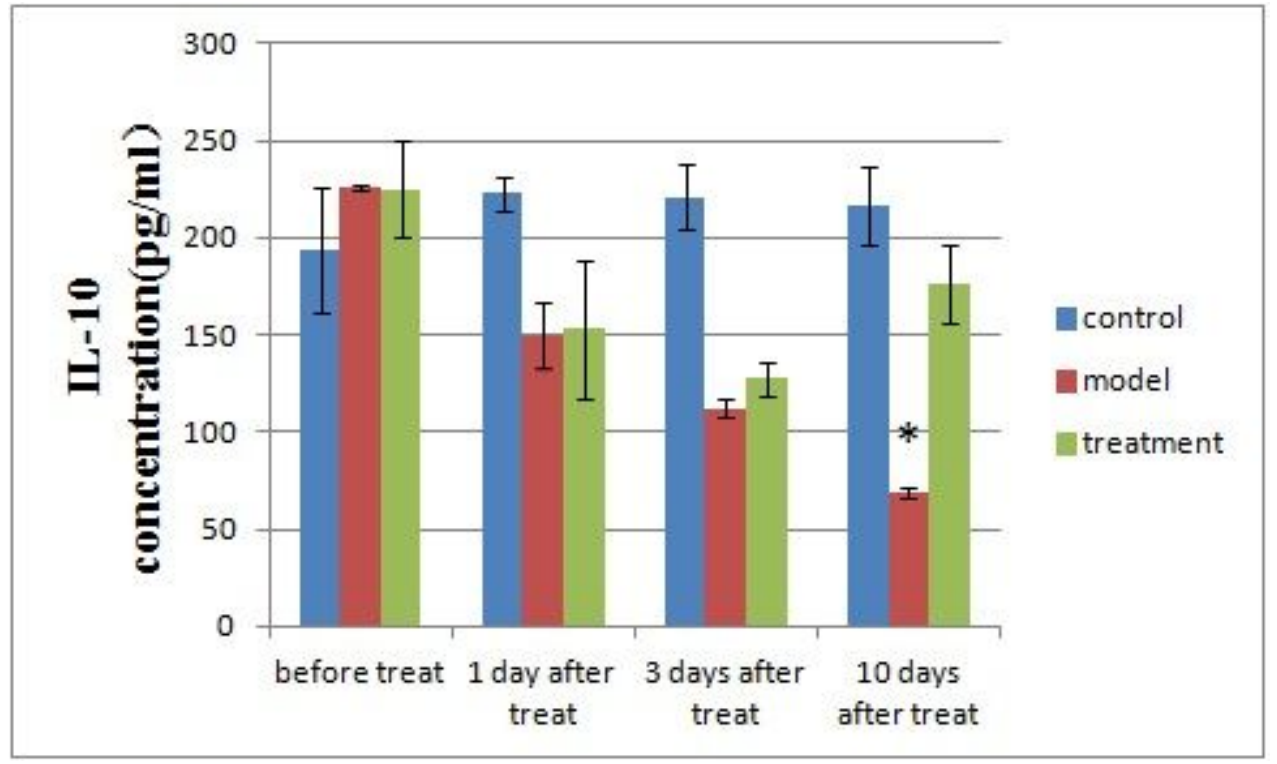

Figure 17

Results of IL-10 detection by ELISA. The results are shown as the mean \pm standard deviation $(n=3)$. * $P$ $<0.01$, compared with the control group.

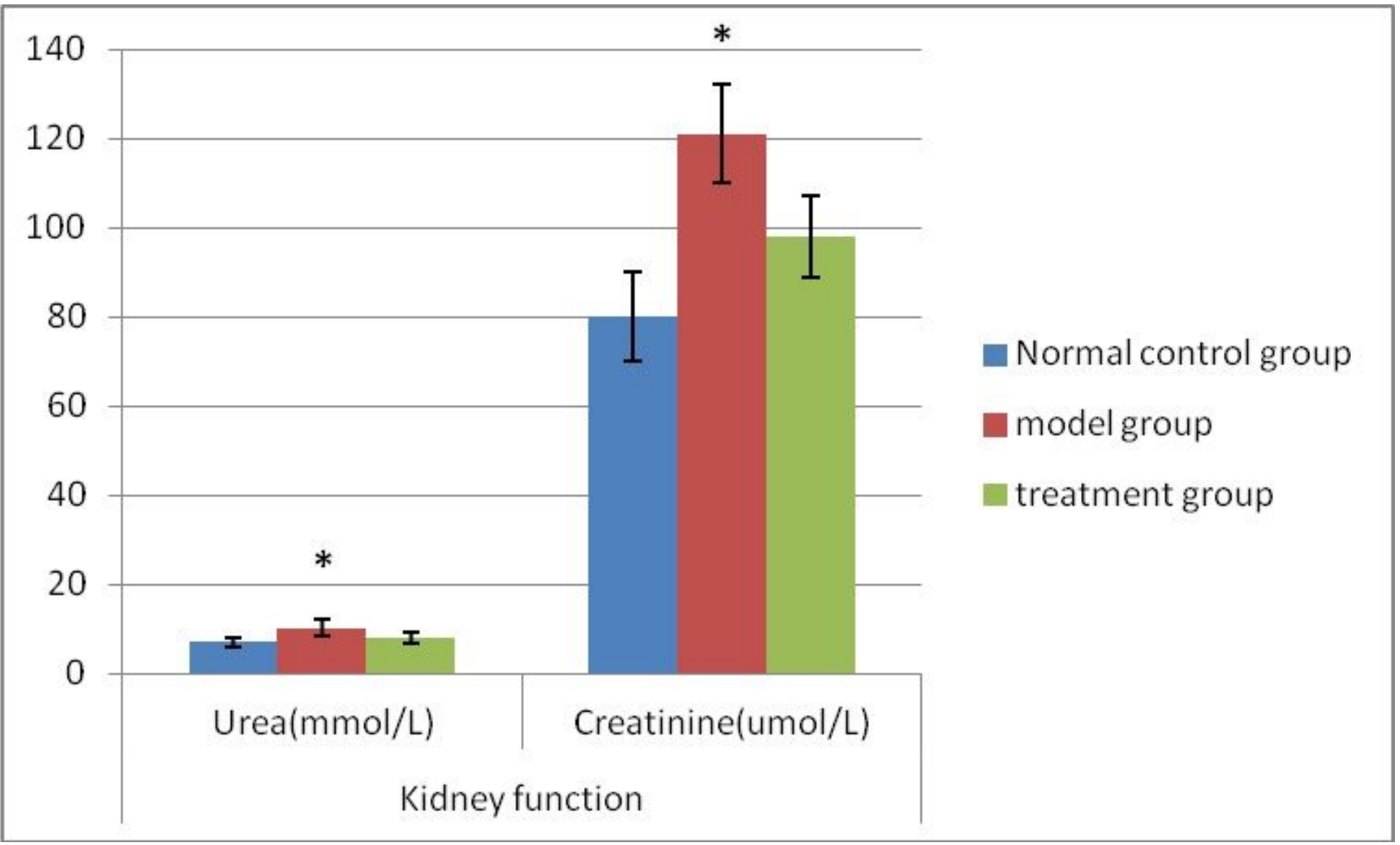

Figure 18 
Results of three groups of renal function tests $(n=5)$. ${ }^{*}<0.01$, the renal function of the model group was significantly higher than that of the normal control group and the treatment group.

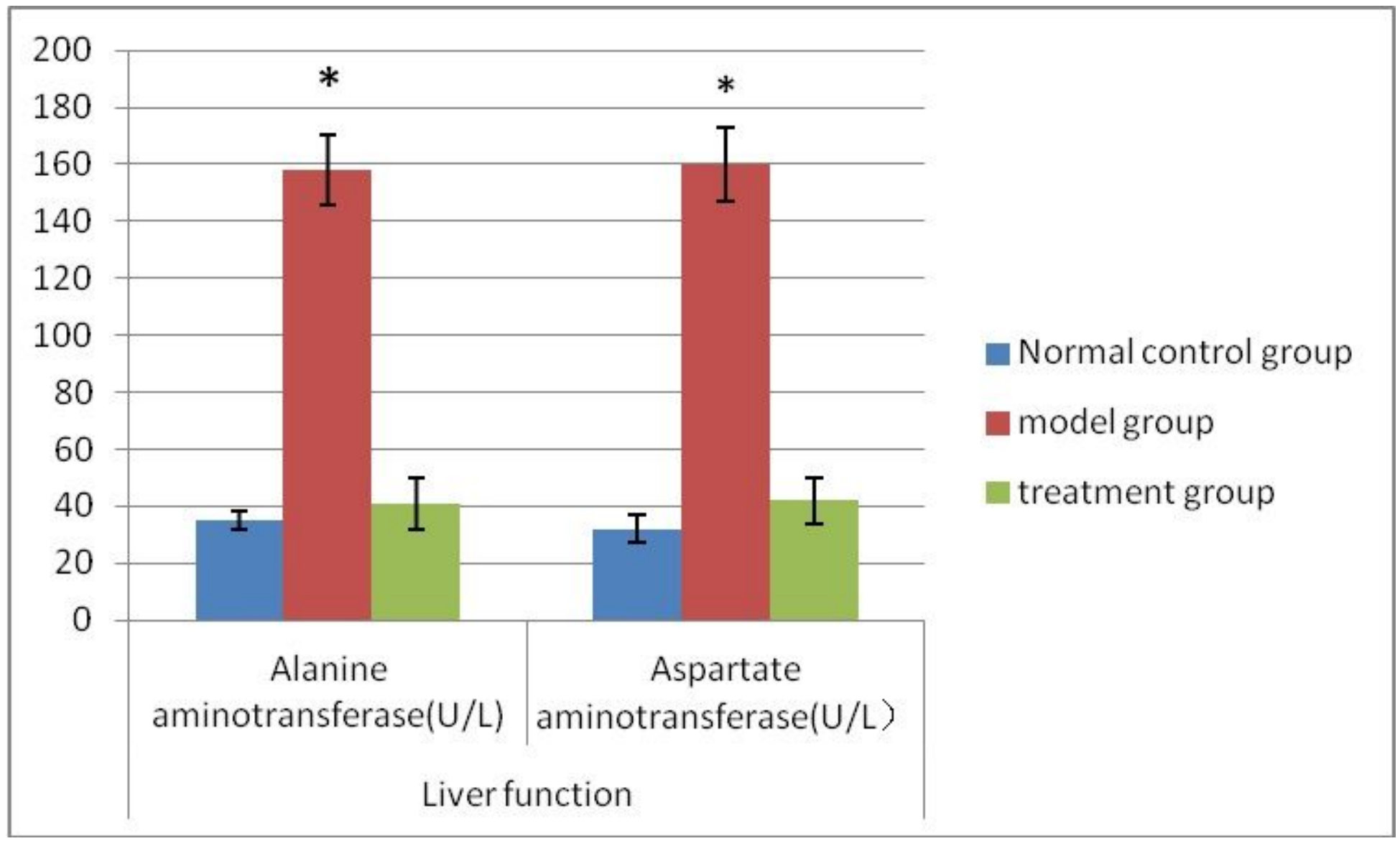

\section{Figure 19}

Results of three groups of liver function tests $(n=5) . * P<0.01$, the liver function of the model group was significantly higher than that of the normal control group and the treatment group. 


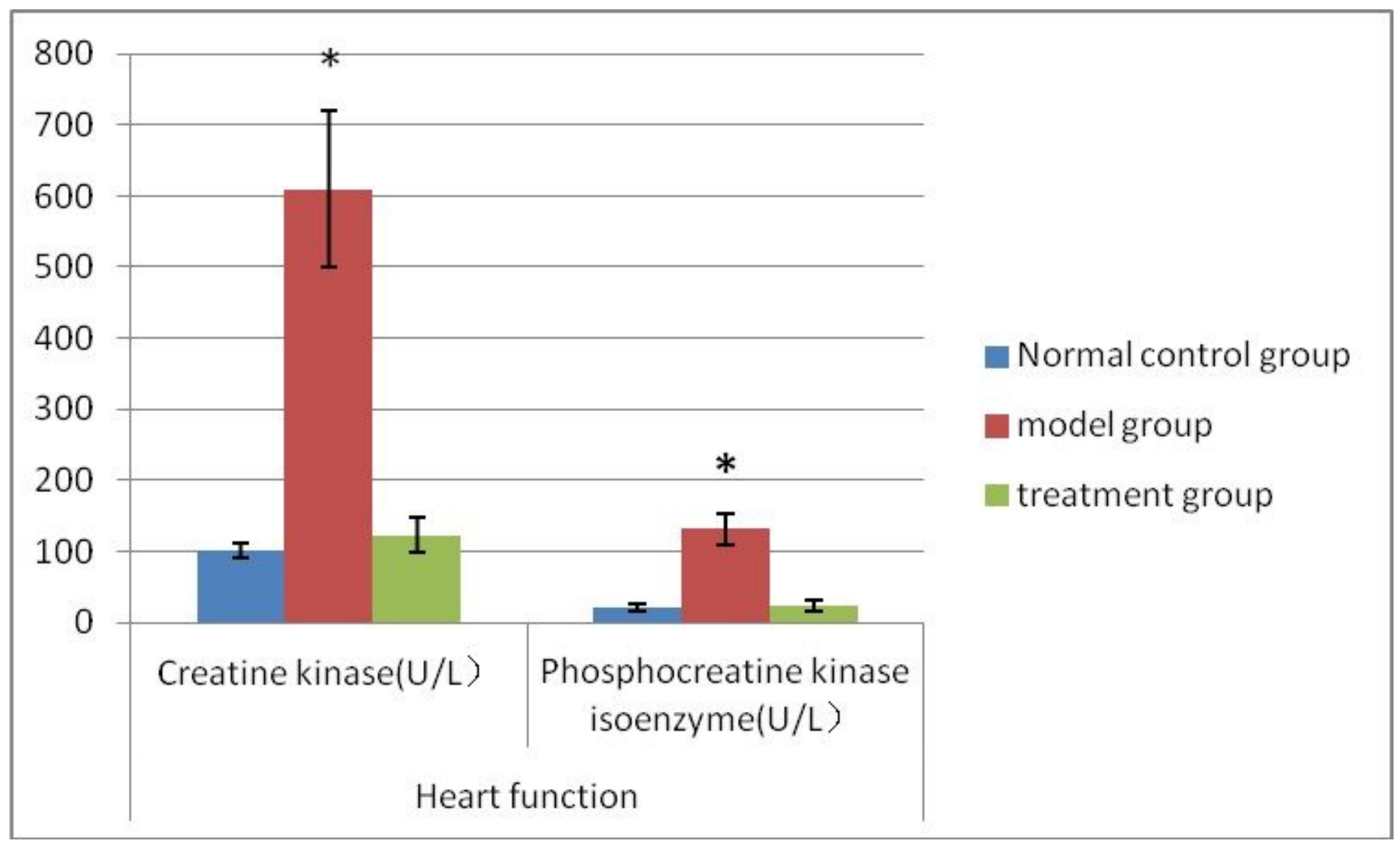

\section{Figure 20}

Results of three groups of heart function tests $(n=5) .{ }^{*}<0.01$, the model group was significantly higher than the normal control group and the treatment group. 